\title{
Dietary habits of Swedish adult coeliac patients treated by a gluten-free diet for 10 years
}

\author{
By Susanne Grehn, Karin Fridell, Margaretha Lilliecreutz and Claes Hallert \\ Received: September 27; Revised: November 15, Accepted November 27, 2001
}

\begin{abstract}
Background: Uncertainty still exists whether coeliac patients living on a gluten-free diet for several years are ensured a nutritionally balanced diet.

Objective: To evaluate the dietary habits of adults with longstanding coeliac disease

Design: The intake of nutrients and foods was assessed in 49 Swedish coeliac patients (32 women) aged 45-64 years treated for 8-12 years using 4-day dietary record. Compliance with the diet was ascertained by showing a villous intestinal structure at repeat biopsy or normal serological tests. The control group ( $\mathrm{n}: 498)$ consisted of a general population sample of same age. Results: The coeliac patients showing the same energy intake as controls had a lower intake of fibre, niacin equivalents, folate, vitamin $\mathrm{B}_{12}$, calcium, phosphorus and zinc. In relation to recommended intakes, low levels of fibres, folate, vitamin $\mathrm{E}$ and selenium were seen in both coeliacs and controls. Significant differences between coeliac patients and controls were seen for half of the food groups under study and this was particularly true for women.

Conclusions: The results suggest that Swedish coeliac patients living on a gluten-free diet for several years need to improve their dietary habits. To this end, regularly visiting a dietitian could be helpful to introduce oat-based options and increase the intake of fresh fruits and greens.

Key words: Coeliac disease, gluten-free diet, nutrition, vitamin
\end{abstract}

\section{Introduction}

Ever since Dicke's discovery of the noxious properties of gluten (1), a gluten-free diet (GFD) is the cornerstone in the treatment of coeliac disease. The rapid improvement in health (2) and return to normal of intestinal mucosa abnormalities (3) are characteristics of the response to treatment. Evidence shows that a lifelong strict GFD is necessary to avoid complications like osteoporosis in patients with coeliac disease (4).

In practice, starting on a GFD means allowing patients to select proper foods by omitting and substituting for gluten containing foods. Whether this ensures an adequate intake of nutrients throughout treatment remains unclear, as studies of patients adhering to a strict diet for years have arrived at conflicting conclusions. Collins (5) reported largely normal findings in adult patients, whereas Mariani (6) studying adolescents found high intakes of protein and fat and low intakes of calcium and dietary fibres and proposed that a GFD may even be a nutritional risk.

A recent finding of ours of hyperhomocysteinaemia in welltreated adults with longstanding coeliac disease (7), indicative of poor vitamin status, prompted us to evaluate the dietary habits of such people. The findings were compared with data obtained from a dietary survey of a general Swedish population of same age (8).

\section{Patients and methods}

The study was performed in 1996-1997 and aimed at collecting and analyzing dietary data from a cohort of middle-aged coeliac patients who had been on a strict GFD for 8-12 years. We recruited 49 patients ( 32 women) out of all 65 living adult coeliac patients aged 45-64 years diagnosed in routine practice at 6 gastroenterology departments in southeast Sweden in 1984-88. Eight patients were excluded after showing persistent intestinal lesions due to non-compliance with the GFD. Five patients refused to participate in the study and 2 had moved outside the area. One patient failed to comply with the protocol. Coeliac

Susanne Grehn, Dietitian, Karin Fridell, Dietitian, Margaretha Lilliecreutz, Dietitian, Claes Hallert*, MD, Ass Prof., Faculty of Health Sciences, Linköping University, Coeliac Centre, B-HoS, SE-581 91 Linköping, Sweden. *Correspondence: E-mail: Claes.Hallert@lio.se patients with concomitant dermatitis herpetiformis were not enrolled.

All patients had the diagnosis confirmed by a jejunal biopsy showing lesions compatible with coeliac disease. They were started on a GFD and showed signs of remission within a year.

Compliance with the diet was ascertained by showing histological signs of remission (n:39) or negative serology tests for gliadin and endomysial antibodies in patients unwilling to undergo endoscopy (n:10). The repeat intestinal biopsy specimens were classified into three groups in accordance with a modification of the Marsh \& Crowe scheme (9) adopted by the Swedish Pathological Society: normal, borderline (that is, more than 25 intraepithelial lymphocytes (IEL) per 100 enterocytes but without the other stigmata of gluten enteropathy), or diagnostic for gluten sensitivity (that is, an increased IEL count, signs of enterocyte damage, or distortion of mucosal architecture). Of the patients thus included in the study, 32 showed a normal biopsy and 7 borderline findings, i.e. findings compatible with a coeliac intestinal mucosa in remission.

The dietary history of coeliac patients was obtained by a 4-day food record, including one holiday. During a visit to the clinic, height and weight were measured and the patients were requested to fill out a form covering smoking habits, current medication and physical activity. All patients were advised by a dietian to continue their usual eating habits and record their intake including snacks in terms of selected foods, e.g. types of milk and bread, as well as how the meals were put together and processed. The ingredients were to be stated as household measures, grams or pieces. The gluten-free products must be given by name and manufacturer. At a follow-up visit, the dietitian and the patient reviewed the food records together. A dietitian translated the record data into weights and portion sizes that were subsequently converted into nutrients by means of the Dietist software (Kost- och näringsdata AB, Stockholm, Sweden) and, concerning foods, the MATs software (Rudans lättdata, Västerås, Sweden). All blood samples were analysed according to local routines, except for zinc analyses, which were carried out centrally by means of atomic-absorption spectrophotometry. 
Control intake data were obtained from a Swedish national dietary survey in 1989 (8). The group comprised 498 subjects (50\% females) aged 45-64 years who were studied over 7 consecutive days including one holiday using a menu book with preprinted options for cooked meals and household measures for remaining meals.

Validation of the food record data was done by comparing the registered energy intake to the calculated basal metabolic rate (BMR) and took into account lifestyle (10) using a relevant physical activity level (PAL) factor as outlined by Black (11). The BMR was predicted from weight, height, age and gender using the Schofield equations (12). For example, a PAL of 1.3 is equivalent with being bedridden and of 1.6 with a sedentary lifestyle with few physical activities.

\section{Statistics}

The results were tested using the t-test. To avoid associations occurring by chance we considered an association as significant $(\mathrm{P}<0.05)$ if true for both men and women or true for at least for either of them with the other showing an association in the same direction.

\section{Ethics}

The study was approved by the Ethics' committee at the Faculty of Health. Sciences, University of Linköping, Sweden.

\section{Results}

Table 1 shows the results of routine blood laboratory investigations in the coeliac patients which were within the normal range, corroborating the state of remission as proved by biopsy and serology.

As shown in Table 2, the energy intake as well as the relative contributions of protein, fat and carbohydrate were in the same range in coeliac patients and controls. The fibre intake, however, was lower in the coeliac patients, as were the intakes of folate, vitamin $\mathrm{B}_{12}$, niacin equivalents, calcium, phosphorus and zinc.
Table 1.Routine laboratory investigations of 49 adult coeliac patients treated by a gluten-free diet for 10 years.

\begin{tabular}{llcc}
\hline & & Mean $\pm \mathrm{SD}$ & Reference range \\
& & & \\
\hline $\begin{array}{l}\text { Body weight } \\
\quad \text { men }\end{array}$ & $\mathrm{kg}$ & $80.7 \pm 10.9$ & \\
$\quad$ women & & $68.9 \pm 10.5$ & \\
$\begin{array}{l}\text { Body mass index } \\
\quad \text { men }\end{array}$ & & & \\
$\quad$ women & & $25.3 \pm 3.5$ & \\
B-Hemoglobin & $\mathrm{g} / \mathrm{L}$ & $25.5 \pm 4.0$ & \\
$\quad$ men & & $145.0 \pm 8.8$ & $130-165$ \\
$\quad$ women & $\mathrm{g} / \mathrm{L}$ & $131.8 \pm 9.5$ & $120-150$ \\
P-Albumin & $\mathrm{mmol} / \mathrm{L}$ & $2.37 \pm 0.8$ & $2.15-2.65$ \\
& $\mu \mathrm{kat} / \mathrm{L}$ & $2.7 \pm 1.0$ & $<4.6$ \\
P-Calcium & $\mu \mathrm{mol} / \mathrm{L}$ & $14.3 \pm 1.3$ & $11.0-17.7$ \\
P-ALP & $\mu \mathrm{g} / \mathrm{L}$ & & \\
S-Zinc & & $115.0 \pm 65.71$ & $30-250$ \\
P-Ferritin & & $76.7 \pm 70.43$ & $30-150$ \\
$\quad$ men & & & $36-48$ \\
$\quad$ women & $\mathrm{mmol} / \mathrm{L}$ & $5.7 \pm 0.99$ & $4.0-8.5 *$ \\
P-Cholesterol & $\mathrm{mmol} / \mathrm{L}$ & & \\
fP-HDL Cholesterol & & $1.2 \pm 0.19$ & $>0.8$ \\
$\quad$ men & & $1.5 \pm 0.48$ & $>0.9$ \\
$\quad$ women & & $3.7 \pm 0.77$ & $<5.0$ \\
fP-LDL-Cholesterol & $\mathrm{mmol} / \mathrm{L}$ & $3.0 \pm 1.12$ & $<5.0$ \\
fP-LDL/HDL-Cholesterol & & $1.5 \pm 1.01$ & $0.4-2.2 *$ \\
fP-Triglycerides & $\mathrm{mmol} / \mathrm{L}$ & $1.5 \pm 1$ & \\
\hline
\end{tabular}

$\mathrm{SD}=\mathrm{Standard}$ deviation. $\mathrm{ALP}=\mathrm{Alkaline}$ phosphatase

By contrast, they tended to show a higher intake than controls of vitamin $\mathrm{E}$, thiamine and vitamin $\mathrm{C}$, particularly true for women.

Relating the intake levels to the NNR, the coeliac patients showed a higher fat energy percentage whereas the carbohydrate energy percentage was lower as were the intake levels of fibres, folate, vitamin E and selenium. As seen in Table 2, this was true

Table 2. Intake of nutrients (mean \pm SD) in adult coeliac patients treated for 10 years and a general population sample.

\begin{tabular}{|c|c|c|c|c|c|c|c|c|}
\hline \multirow{2}{*}{ Daily intake } & & \multicolumn{3}{|c|}{ Women } & \multicolumn{2}{|c|}{ Men } & \multirow[b]{2}{*}{$\mathrm{P}$} & \multirow[b]{2}{*}{ NNR *** } \\
\hline & & Coeliacs (n:31) & Controls (n:248) & $\mathrm{P}$ & Coeliacs (n:18) & Controls (n:250) & & \\
\hline \multirow{2}{*}{ Energy } & MJ & $7.3 \pm 1.7$ & $7.4 \pm 2.3$ & ns & $9.2 \pm 1.8$ & $9.3 \pm 2.5$ & ns & \\
\hline & Kcal & $1754 \pm 412.5$ & $1766 \pm 541.8$ & ns & $2198 \pm 432.1$ & $2218 \pm 603.8$ & $\mathrm{~ns}$ & \\
\hline \multirow[t]{2}{*}{ Protein } & $\mathrm{g}$ & $62.5 \pm 12.1$ & $65.2 \pm 13.9$ & ns & $81.4 \pm 13.7$ & $81.0 \pm 19.6$ & ns & \\
\hline & $\mathrm{E} \%$ & $15 \pm 2.9$ & $15 \pm 3.2$ & $\mathrm{~ns}$ & $15 \pm 2.6$ & $15 \pm 2.4$ & ns & $10-15$ \\
\hline \multirow[t]{2}{*}{ Fat } & $\mathrm{g}$ & $68.3 \pm 24.5$ & $69.6 \pm 22.7$ & ns & $92.1 \pm 23.1$ & $93.0 \pm 33.5$ & ns & \\
\hline & $\mathrm{E} \%$ & $34 \pm 6.3$ & $36 \pm 7.2$ & ns & $37 \pm 4.9$ & $37 \pm 8.0$ & ns & $<30$ \\
\hline \multirow[t]{2}{*}{ Carbohydrate } & g & $220 \pm 56.7$ & $209 \pm 59.2$ & ns & $254 \pm 57.9$ & $248 \pm 76.2$ & ns & \\
\hline & $\mathrm{E} \%$ & $51 \pm 5.8$ & $48 \pm 7.2$ & $<0.05$ & $47 \pm 6.5$ & $45 \pm 8.8$ & ns & $55-60$ \\
\hline Fibre & $\mathrm{g}$ & $11.5 \pm 4.3$ & $16.0 \pm 4.8$ & $<0.000$ & $10.0 \pm 3.3$ & $17.3 \pm 5.9$ & $<0.000$ & $25-30$ \\
\hline Vitamin $\mathrm{A}^{*}$ & $\mathrm{mg}$ & $1.3 \pm 0.6$ & $1.4 \pm 0.8$ & ns & $1.1 \pm 0.6$ & $1.6 \pm 1.1$ & ns & $0.8(1.0)$ \\
\hline Vitamin D & $\mu \mathrm{g}$ & $4.6 \pm 1.9$ & $4.8 \pm 1.7$ & $\mathrm{~ns}$ & $5.3 \pm 3.2$ & $6.4 \pm 2.8$ & ns & 5 \\
\hline Vitamin $\mathrm{E}^{* *}$ & $\mathrm{mg}$ & $7.4 \pm 2.9$ & $6.1 \pm 2.0$ & $<0.005$ & $7.4 \pm 4.2$ & $7.5 \pm 3.4$ & ns & $8(10)$ \\
\hline Vitamin C & $\mathrm{mg}$ & $112 \pm 71.6$ & $76 \pm 42.7$ & $<0.000$ & $76 \pm 54.3$ & $68 \pm 39.0$ & ns & 60 \\
\hline Thiamine & $\mathrm{mg}$ & $1.3 \pm 0.3$ & $1.1 \pm 0.3$ & $<0.05$ & $1.4 \pm 0.4$ & $1.4 \pm 0.4$ & ns & $1.1(1.4)$ \\
\hline Riboflavin & $\mathrm{mg}$ & $1.5 \pm 0.3$ & $1.6 \pm 0.5$ & ns & $1.8 \pm 0.5$ & $1.9 \pm 0.7$ & ns & $1.3(1.6)$ \\
\hline Niacin equivalents & $\mathrm{mg}$ & $23.2 \pm 5.6$ & $25.6 \pm 5.7$ & $<0.05$ & $31.1 \pm 5.5$ & $32.6 \pm 8.3$ & ns & $15(18)$ \\
\hline Vitamin $\mathrm{B}_{6}$ & $\mathrm{mg}$ & $1.7 \pm 0.4$ & $1.7 \pm 0.5$ & ns & $1.9 \pm 0.4$ & $2.1 \pm 0.6$ & ns & $1.2(1.5)$ \\
\hline Vitamin $B_{12}$ & $\mu g$ & $4.3 \pm 2.2$ & $6.9 \pm 5.1$ & $<0.000$ & $5.3 \pm 1.9$ & $8.9 \pm 7.2$ & $<0.05$ & 2.0 \\
\hline Folate & $\mu g$ & $186 \pm 54.9$ & $197 \pm 56.6$ & ns & $172 \pm 55.8$ & $215 \pm 64.4$ & $<0.01$ & 300 \\
\hline Calcium & $\mathrm{mg}$ & $837 \pm 241.1$ & $973 \pm 303.0$ & $<0.05$ & $999 \pm 391.9$ & $1083.0 \pm 434.0$ & ns & 800 \\
\hline Phosphorus & $\mathrm{mg}$ & $1058 \pm 229.9$ & $1267 \pm 309.1$ & $<0.001$ & $1314 \pm 249.2$ & $1520 \pm 441.0$ & $<0.05$ & 600 \\
\hline Zinc & $\mathrm{mg}$ & $7.7 \pm 1.8$ & $8.9 \pm 2.0$ & $<0.001$ & $10.2 \pm 1.7$ & $11.1 \pm 3.1$ & $\mathrm{~ns}$ & $7(9)$ \\
\hline Selenium & $\mu g$ & $30.0 \pm 8.6$ & $29.6 \pm 8.3$ & ns & $33.9 \pm 12.1$ & $36.6 \pm 11.3$ & ns & $40(50)$ \\
\hline
\end{tabular}

*Retinol equivalents; $* * \alpha$-tocopferol equivalents; *** Nordic Nutrition Recommendations women (men) (13); ns=not significant 
Table 3. Number $(\%)$ of coeliac patients that failed to meet recommended intake levels for some selected nutrients.

\begin{tabular}{lcc}
\hline Nutrient & $\begin{array}{c}\text { Women } \\
(\mathrm{n}: 31)\end{array}$ & $\begin{array}{c}\text { Men } \\
(\mathrm{n}: 18)\end{array}$ \\
\hline Fibre & $31(100)$ & $18(100)$ \\
Vitamin C & $7(23)$ & $9(50)$ \\
Vitamin D & $19(61)$ & $7(39)$ \\
Vitamin $\mathrm{B}_{6}$ & $1(3)$ & $1(6)$ \\
Folatc & $30(97)$ & $18(100)$ \\
Calcium & $13(42)$ & $6(33)$ \\
Zinc & $12(39)$ & $3(17)$ \\
& & \\
\hline
\end{tabular}

also for the controls. Table 3 shows the frequency among the coeliac patients is shown of intake levels below recommendations (NNR) for selected nutrients.

Regarding food choices (Table 4), the coeliac patients took more crème and sausage and less dairy fat, pizza and pancake among fat-rich foods. For protein-rich foods they ate more meat and poultry and less of milk and yoghurt. The coeliac patients used rice, corn flakes, root vegetables, greens (women) and sweets as major sources of carbohydrate whereas the control subjects ate more porridge and pasta.

The energy intakes were low in both patients and controls and even below reference values for groups with low physical activity. The diet records of the coeliac patients were thus validated by comparing the energy/ BMR-ratio $(1,30 \pm 0,30)$ (mean \pm SD) to the PAL $(1,72 \pm 0,20)$ and revealed an underestimation of the energy intake by $25 \%$ (women $23 \%$, men $28 \%$ ), same as reported for controls (mean $25 \%$ ).

\section{Discussion}

To our knowledge, this is the first study comparing the dietary habits of well-treated adult coeliac patients with a general population sample. It took into account the intake of nutrients and foods and revealed significant differences between the groups, as well as deviations from recommended intake levels. The results imply that taking a GFD for 10 years does not entail a nutritionally balanced diet.

The coeliac patients showed an intake of folate, which was lower than in controls and far below the recommended level. Interestingly, this is corroborated by the results of a recent study (7) measuring the plasma total homocysteine level, a metabolic marker of folate, vitamin $B_{6}$ and vitamin $B_{12}$ deficiencies (14). We found 16 out of $39(41 \%)$ adults with longstanding coeliac disease in morphologic remission had a raised homocysteine concentration. It was negatively related to the plasma levels of folate and pyridoxal 5'-phosphate (active form of vitamin $\mathrm{B}_{6}$ ), suggesting the hyperhomocysteinaemia to be nutritional in origin. Of interest in this connection, an elevated plasma homocysteine level is currently regarded as an independent risk factor for various conditions, such as vascular disease (15), adverse pregnancy outcomes (16), venous thromboembolic disease (17) and neurocognitive dysfunction (18). Thus, our results may raise serious concerns over the adequacy of the diet taken by adult coeliac patients treated for several years.

Starting on a GFD may have a profound impact on later food choices, a largely neglected issue in studies of the management of coeliac disease. From our experience, this is particularly true for adults who are compelled to abandon their breakfast habits by abstaining from common breads and, to some extent, porridge. We found that the present series, although taking more flakes and

Table 4. Comparison (mean \pm SD) of food choices of adult coeliac patients treated for 10 years and a general population sample.

\begin{tabular}{|c|c|c|c|c|c|c|}
\hline Daily intake (g) & Coeliacs (n:31) & $\begin{array}{c}\text { Women } \\
\text { Controls (n:248) }\end{array}$ & $\mathrm{P}$ & Coeliacs (n:18) & $\begin{array}{l}\text { Men } \\
\text { Controls (n:250) }\end{array}$ & $\mathrm{P}$ \\
\hline Dairy fats & $10 \pm 6.8$ & $15 \pm 13.8$ & $<0.05$ & $19 \pm 14.0$ & $31 \pm 25.2$ & $<0.05$ \\
\hline Cheese & $32 \pm 26.9$ & $37 \pm 19.5$ & ns & $49 \pm 33.3$ & $41 \pm 25.2$ & $\mathrm{~ns}$ \\
\hline Milk, yoghurt & $254 \pm 143.7$ & $327 \pm 184.2$ & $<0.05$ & $296 \pm 258.8$ & $382 \pm 307.0$ & $\mathrm{~ns}$ \\
\hline Bread & $79 \pm 47.1$ & $80 \pm 28.7$ & ns & $111 \pm 38.1$ & $112 \pm 46.2$ & ns \\
\hline Potato & $127 \pm 66.3$ & $113 \pm 56.5$ & ns & $188 \pm 94.5$ & $186 \pm 97.6$ & ns \\
\hline Root vegetables & $31 \pm 29.5$ & $12 \pm 17.2$ & $<0.000$ & $22 \pm 34.1$ & $8 \pm 11.6$ & $<0.000$ \\
\hline Greens & $138 \pm 77.2$ & $89 \pm 63.1$ & $<0.000$ & $69 \pm 64.4$ & $71 \pm 52.8$ & ns \\
\hline Fruits & $133 \pm 94.2$ & $160 \pm 112.6$ & ns & $71 \pm 89.0$ & $117 \pm 112.5$ & $\mathrm{~ns}$ \\
\hline Juice & $56 \pm 71.1$ & $53 \pm 82.4$ & $\mathrm{~ns}$ & $35 \pm 64.1$ & $39 \pm 73.2$ & ns \\
\hline Porridge & $17 \pm 48.7$ & $61 \pm 81.7$ & $<0.005$ & $21 \pm 40.5$ & $59 \pm 91.0$ & ns \\
\hline Flakes, müsli & $8 \pm 12.5$ & $4 \pm 6.2$ & $<0.005$ & $12 \pm 15.6$ & $4 \pm 9.0$ & $<0.005$ \\
\hline Pancake & $10 \pm 25.2$ & $11 \pm 17.7$ & ns & $5 \pm 18.2$ & $17 \pm 3.3$ & $<0.000$ \\
\hline Rice, grains & $24 \pm 27.2$ & $13 \pm 20.5$ & $<0.005$ & $30 \pm 59.5$ & $16 \pm 25.0$ & $<0.05$ \\
\hline Pasta & $3 \pm 7.4$ & $8 \pm 11.5$ & $<0.05$ & $3 \pm 7.2$ & $11 \pm 11.6$ & $<0.005$ \\
\hline Peas, beans & $5 \pm 17.2$ & $6 \pm 13.3$ & ns & $8 \pm 30.3$ & $14 \pm 26.0$ & ns \\
\hline Meat, poultry & $85 \pm 53.1$ & $70 \pm 36.6$ & $<0.05$ & $135 \pm 44.6$ & $97 \pm 44.0$ & $<0.001$ \\
\hline Egg, egg dishes & $24 \pm 19.4$ & $16 \pm 13.8$ & $<0.005$ & $24 \pm 29.5$ & $21 \pm 23.1$ & ns \\
\hline Fish, seafood & $33 \pm 33.8$ & $33 \pm 25.2$ & ns & $52 \pm 73.0$ & $37 \pm 32.8$ & ns \\
\hline Visceral foods & $5 \pm 6.8$ & $6 \pm 7.7$ & ns & $4 \pm 7.6$ & $8 \pm 11.0$ & ns \\
\hline Sausage & $32 \pm 38.7$ & $16 \pm 13.8$ & $<0.000$ & $64 \pm 49.4$ & $26 \pm 19.5$ & $<0.000$ \\
\hline Biscuits & $43 \pm 35.8$ & $51 \pm 39.0$ & ns & $54 \pm 38.7$ & $44 \pm 44.3$ & ns \\
\hline Ice cream & $12 \pm 22.3$ & $14 \pm 21.1$ & ns & $6 \pm 14.1$ & $10 \pm 15.6$ & ns \\
\hline Crème & $11 \pm 14.3$ & $4 \pm 6.2$ & $<0.000$ & $14 \pm 18.4$ & $3 \pm 7.0$ & $<0.000$ \\
\hline Desserts & $40 \pm 60.5$ & $23 \pm 36.6$ & $<0.05$ & $20 \pm 39.9$ & $23 \pm 66.6$ & ns \\
\hline Marmelade & $18 \pm 19.0$ & $9 \pm 8.3$ & $<0.000$ & $13 \pm 18.2$ & $12 \pm 13.8$ & ns \\
\hline Lemonade & $92 \pm 94.3$ & $69 \pm 108.8$ & ns & $186 \pm 209.0$ & $82 \pm 134.6$ & $<0.005$ \\
\hline Candies & $15 \pm 18.4$ & $5 \pm 9.8$ & $<0.000$ & $10 \pm 11.7$ & $4 \pm 10.0$ & $<0.05$ \\
\hline Sugar honey & $8 \pm 15.0$ & $4 \pm 8.3$ & $<0.05$ & $17 \pm 17.7$ & $8 \pm 11.6$ & $<0.005$ \\
\hline
\end{tabular}

ns=not significant 
müsli than controls, were unable to cope with proper substitutes for fibre rich products, resulting in a low intake of dietary fibres. Interestingly, this was not seen in newly diagnosed dermatitis herpetiformis patients followed by Björkman et al. (19) over an 18-month period.

We think that allowing oats to be included in the GFD (20) would help coeliac patients to resume much of their early dietary habits and hence increasing the intake of dietary fibres and possibly thiamine, niacin equivalents and zinc. This may have important clinical implications since treated coeliac patients frequently complain of gastrointestinal symptoms also when in remission (21). In fact, this has been suggested to be a factor behind the reduced well-being in this patient group (2).

The intake level of bread was similar in coeliac patients and controls, which would suggest that the availability in Sweden of gluten-free breads through baking and purchasing, or both, is sufficient to meet the demands. However, the relative contributions of dietary fibre and folate intakes from bread were generally lower in coeliac patients than in the controls: for fibre $28 \%$ vs $38 \%$ (ns) and for folate $9 \%$ vs $21 \%(\mathrm{P}<0.03)$.

The lower intake of milk and milk-containing products in the coeliac patients may be a cause for concern. It might well be a remnant of the dietary instructions given at diagnosis aiming at temporarily limit the intake of milk awaiting the return of mucosal lactase activity. However, the clinical implication of low intake of milk-containing products in coeliac disease is incompletely understood. It could well be that complete withdrawal of dietary gluten to heal the intestinal mucosa is sufficient to ensure an optimal bone mineral content of these people (22).

The tendency for coeliac patients to take less fat would seem favourable but was offset by a higher intake of crème and sausage. The relatively higher energy intake from fat and lower energy intake from carbohydrate was proposed by Mariani (6) to be a nutritional risk factor in treated coeliac disease. It received no support in the present study, which showed virtually normal plasma lipid patterns. In fact, a HDL-cholesterol level of $>1$ $\mathrm{mmol} / \mathrm{L}$, the cut-off level set for a raised risk for cardiovascular disease in primary prevention, was displayed by all but $2(4 \%)$ in the present series.

For an individual coeliac subject under treatment, the risk of developing malignant diseases is small. Yet, malignant lymphomas are commoner than in the general population and closely linked to the daily amount of ingested gluten (23). Pharyngeal and oesophageal carcinoma, another condition occurring more often in coeliac patients (24), may be causally related to a low dietary intake of antioxidants, like vitamin $C$, vitamin $E$ and $\beta$ carotene. Reassuringly, we found that female coeliac patients took a diet fairly rich in fresh fruits and greens, including juice (mean, $360 \mathrm{~g} /$ day), i.e. close to the range thought to protect against the development of such malignancies (400-600 g/day) (25-26). For coeliac men, the corresponding figure, $190 \mathrm{~g} /$ day, stands out as a cause for concern.

The assessment of nutrient and food intake is a matter of current contention (27). Like Kemppainen (28), we chose to collect dietary data over 4 days to ensure patient compliance in contrast to the 7-day period used for controls. It was done in the belief that recordings lasting longer may not necessarily be superior (29). Indeed, a fair estimate of the skewed intake of vitamin $B_{12}$ would require a sampling period lasting at least 15 days according to the formula of Beaton (30). Also, the measurement can be associated with bias such as changes during the study in normal dietary patterns or underreporting or both, as reflected by the discrepancy between the mean ratio of reported energy intake to BMR of 1.32 in the coeliac patients and the mean self-assessed PAL of 1.70. Of interest, a third of the coeliac population was either on sick leave or being granted disability pension. Having recorded the same energy levels in the coeliac sample and controls and a similar range of underestimating the energy intake, we believe the discrepancies observed are real and not accounted for by the different methods used to collect the data. It may be that controlling the variation among study subjects is of greater importance in this regard (31).

The loss through industrial and household food processing and the uncertainty of the bioavailability of nutrients in humans (3233) are other factors that tend to reduce the scientific values of food records, unless interpreted in combination with other clinical data. Thus, low intake of selenium in the coeliac patients in relation to the NNR value would suggest poor selenium status in as much as the availability of selenium in the soil is low in Scandinavia. Yet, we found a normal serum selenium level in all but one in our series in keeping with a report on treated Danish coeliac patients (34).

The strength of the study comprises its originality exploring the dietary habits of adult coeliac patients living on a strict GFD for 10 years, as proved by biopsy and serology. We were anxious to validate the food record data by comparing the registered energy intake to the calculated basal metabolic rate. The study has several limitations, which include lack of assessment of the fat quality and the incomplete data of the mineral and vitamin supplements taken by the patients. Furthermore, the results may not necessarily apply to coeliac patients living outside Sweden. Finally, while there is no evidence of regional differences in dietary habits in the areas concerned (8), it could be argued that changes may have occuirred between the time of the surirvey of controls and that of the coeliac population. However, according to preliminary data obtained from Riksmaten (35), a second national dietary survey carried out by the Swedish National Food Administration in 1997-98, it would seem that no dramatic changes in dietary habits have taken place in Sweden over the past decade.

In conclusion, the GFD taken by Swedish adult coeliac patients appears to be nutritionally unbalanced and in need of improvement in certain respects. To this end, we firmly believe that regularly visiting a dietitian should be an urgent component of the surveillance of coeliac disease, as it is in the care of diabetes patients. One important step to ensure a more adequate diet would be to encourage coeliac patients to introduce oatbased options into the diet, as well as increase their intake of fresh fruits and greens.

\section{ACKNOWLEDGEMENTS}

We are grateful for the assistance of Kerstin Ramfelt, Monica Skoglund, Camilla Svensson, Agnetha Uhr. Wulf Becker at the National Food Administration kindly provided data from the HULK survey. The work was supported by a grant from the Medical Research Council of Southeast Sweden.

\section{REFERENCES}

1. Dicke WK: Coeliac disease. Investigation of the harmful effects of certain types of cereal on patients suffering from coeliac disease. MD thesis. Utrecht: University of Utrecht, 1950.

2. Lohiniemi S, Mustalahti K, Collin P, Mäki M: Measuring quality of life in coeliac disease patients. In: Lohiniemi S, Collin P, Mäki M, editors. Changing features of coeliac disease. Tampere: The Finnish Coeliac Society 1998: p.73-7.

3. MacDonald WC, Brandborg LL, Flick AL, Trier JS, Rubin CE: Studies of celiac sprue. IV. The response of the whole length of the small bowel to a gluten-free diet. Gastroenterol 1964;47:573-89.

4. Valdimarsson T, Toss G, Ross I, Löfman O, Ström M: Bone mineral density in coeliac disease. Scand J Gastroenterol 1994;29:457-61.

5. Collins BJ, Bell PM, Thomson JM, Fee DB, Wilson EA, Love AHG: Dietary history and nutritional state in treated coeliac patients. J Roy Soc Med 1986;79:206-9.

6. Mariani P, Grazia Viti M, Montuori M, La Vecchia A, Cipolletta E, Calvani L et al.: The gluten-free diet: A nutritional risk factor for adolescents with celiac disease. JPGN 1998;27:519-23.

7. Hallert C, Lilliecreutz M, Fridell K, Grant C, for the Southest Sweden Adult Coeliac Disease Study Group: High plasma homocysteine in adult coeliac patients in remission: challenging the nutritional adequacy of the glutenfree diet. In: Auricchio S, Greco L, Maiuri L, Troncone R, eds. Eighth 
International Symposium on Coeliac Disease. Naples: Dept of Paediatrics, University of Federico II, 1999:142.

8. Becker W: Food habits and nutrient intake in Sweden 1989. Uppsala: National Food Administration, 1994.

9. Marsh MN, Crowe PT: Morphology of the mucocal lesions in gluten sensitivity. Clin Gastroenterol 1995;9:273-93.

10. Hambræus L: Dietary assessments: how to validate primary data before conclusions can be drawn. Scand J Nutr 1998;42:66-8.

11. Black AE, Coward WA, Cole TJ, Prentice AM: Human energy expenditure in affluent societies: an analysis of 574 doubly-labelled water measurements. Eur J Clin Nutr 1996;50:72-92.

12. Schofield WN, Schofield C, James WPT: Basal metabolic rate. Hum Nutr Clin Nutr 1985;39C (Suppl 1):5-41.

13. Nordic Nutrition Recommendations 1996: (Köpenhamn: Nordiska Ministerrådet Nord 1996:28). Scand J Nutr;40:161-5.

14. Ubbink JB: Metabolic markers of vitamin nutritional status. Am J Clin Nutr 1999;70:789-90.

15. Nygård $\mathrm{O}$, Vollset SE, Refsum $\mathrm{H}$, Brattström L, Ueland PM: Plasma homocysteine and cardiovascular disease. J Intern Med 1999;246:425-54.

16. Vollset SE, Refsum H, Irgens LM, Mork Emblem B, Tverdal A, Gjessing HK et al.: Plasma total homocysteine, pregnancy complications and adverse pregnancy outcomes: The Hordaland homocysteine study. Am J Clin Nutr 2000;71:962-8.

17. Ray JG: Meta-analysis of hyperhomocysteinemia asa risk factor for venous thromboembolic disease. Arch Intern Med 1998;158:2101-6.

18. Selhub J, Bagley LC, Miller J, Rosenberg IH: B vitamins, homocysteine, and neurocognitive function in the elderly. Am J Clin Nutr 2000;71 (suppl): $614 \mathrm{~S}-20 \mathrm{~S}$

19. Björkman A-C, Mobacken H, Kastrup W, Andersson H: Changes in food consumption and its nutritional quality when on a gluten-free diet for dermatitis herpetiformis. Human Nutr Appl Nutrition 1985;39A:124-9.

20. Hallert C, Olsson M, Størsrud S, Arvidsson Lenner R, Kilander A, Stenhammar L: Oats can be included in gluten-free diets. Läkartidningen 1999;96:3339-40 (In Swedish).

21. Hallert C, Grännö C, Grant C, Hultén S, Midhagen G, Ström M et al.: Quality of life of adult coeliac patients treated for 10 years. Scand J
Gastroenterol 1998:33:933-8.

22. Valdimarsson T, Löfman O, Toss G, Ström M: Reversal of osteopenia with diet in adult coeliac disease. Gut 1996;38:322-7

23. Holmes GKT, Prior P, Lane MR, Pope D, Allen RN: Coeliac disease and malignancy - effect of a gluten-free diet. Gut 1989;30:333-8.

24. Swinson CM, Slavin G, Coles EC, Booth CC: Coeliac disease and malignancy. Lancet 1983;i:111-15.

25. Preventing disease - by antioxidants SBU-rapport 135/2:2. Stockholm: The Swedish council for assessment in health care. 2000, p 49-63 (In Swedish).

26. Frugt og grøntsager. Anbefalinger for indtagelse. Ministeriet for Fødevarer, Landbrug og Fiskeri. Køpenhavn: Veterinær-og Fødevaredirektoratet, Publikation nr 244, 1988 (In Danish).

27. SchaeferEJ, Augustin JL SchaeferMM, Rasmussen H, Ordovas JM, Dallal GE, Dwyer JT: Lack of efficacy of a food-frequency questionnaire in assessing dietary macronutrient intake in subjects consuming diets of known composition. Am J Clin Nutr 2000;71:746-51.

28. Kemppainen T, Uusitupa M, Janatuinen E, Järvinen R, Julkunen R, Pikkarainen P: Intakes of nutrients and nutritional status in coeliac patients. Scand J Gastroenterol 1995;30:575-9.

29. Livingstone MBE, Prentice AM, Strain JJ, Coward WA, Black AE, Barker ME et al. Accuracy of weighted dietary records in studies of diet and health. BMJ 1990;300:708-12.

30. Beaton GH, Milner J, Coery P, McGuire V, Cousins M, Stewart E et al. Source of variance in 24-hour dietary recall data: implications for nutrition study design and interpretation. J Clin Nutr 1979;32:2546-59

31. Black AE, Cole TJ: Biased over- or underreporting is characteristic of individuals whether over time or by different assessment methods. Am Diet Assoc 2001;101:70-80

32. Sandström B, Lönnerdal B: Promoters and antagonists on zinc absorption. In: Mills CF, editor. Zinc in human biology. Berlin: Springer-Verlag. 1989 p 57-8.

33. Witthöft CM, Forssén K, Johannesson L Jägerstad M: Folates - food sources, analyses, retention and bioavailability. Scand J Nutr 1999;43:138-46.

34. Bodé S, Thorling E, Gudmand-Høyer E: Selenium in adult treated coeliac disease. Scand J Nutr 1992;36:2-3.

35. Becker W: Results of the second national Swedish dietary survey. Vår Föda 1999;51:6 